\title{
A questão da Autonomia Universitária e suas vicissitudes na universidade brasileira
}

\author{
Dermeval Saviani
}

Pesquisador Emérito do Conselho Nacional de Desenvolvimento Científico e Tecnológico (CNPq), Coordenador Geral do HISTEDBR e Professor Titular Colaborador Permanente da Pós-Graduação em Educação da Universidade Estadual de Campinas (UNICAMP)

\section{Resumo}

Partindo da origem e desenvolvimento da instituição universitária e da indicação dos modelos básicos de sua organização, este artigo aborda, no segundo momento, a trajetória da universidade no Brasil para, no terceiro momento, tratar das vicissitudes do princípio da Autonomia Universitária na educação brasileira. Finalmente, à guisa de conclusão, abre uma discussão sobre o significado da Autonomia Universitária e as condições para sua implementação na universidade brasileira.

Palavras-chave Educação brasileira - Universidade - Autonomia Universitária.

\section{Abstract}

Starting from the origin and development of the university institution and the indication of the basic models of its organization, this article discusses, in the second moment, the trajectory of the university in Brazil to, in the third moment, address the vicissitudes of the principle of University Autonomy in Brazilian education. Finally, by way of conclusion, opens a discussion about the meaning of University Autonomy and the conditions for its implementation in the Brazilian university.

Keywords Brazilian Education - University - University Autonomy.

\section{Submissão}

22/12/2020 Publicação

09/0I/202I 


\section{Origem e situação atual da universidade ${ }^{\mathrm{I}}$}

$\mathrm{E}$ mbora se possa encontrar referência a universidades desde o ano 737 no mundo árabe, a universidade considerada a mais antiga é a de Bolonha pois, ao que consta, foi com sua criação que surgiu o termo "universidade".

A Universidade de Bolonha data do final do século XI, mais precisamente, do ano de Io88, quando se pode constatar, através de documentos, o ensinamento de Irnério se desenvolvendo, na relação com seus alunos, com as características próprias daquilo que veio a definir a natureza da instituição universitária, conforme esclarece Gian Paolo Brizzi, principal historiador das universidades na Itália. ${ }^{2}$

Além da Universidade de Bolonha cabe destacar a Universidade de Paris criada junto à Basílica de Notre Dame por volta da segunda metade do século XII. Enquanto a universidade de Paris se projetou pelos estudos de teologia, Bolonha se notabilizou pelos estudos jurídicos. De fato, o grande acontecimento, o "milagre bolonhês", que deu origem à Universidade de Bolonha foi a "redescoberta integral do corpus Iuris Civilis, a sua reconstituição filológica e a invenção de um novo sistema para o estudo jurídico: a glosa."

Em Bolonha, assim como na Itália em geral, predominou o espírito laico, ao passo que na França e na Alemanha prevaleceu a iniciativa clerical. ${ }^{4}$ Por outro lado, se a universidade de Paris se constituiu como corporação de professores que incorporou, sob sua direção, também os estudantes, Bolonha se organizou como corporação de estudantes que contratava os mestres exigindo deles a prestação dos cursos previstos. ${ }^{5}$

Sobre a origem da instituição universitária cabe ainda destacar suas diferentes formas. Assim, algumas universidades como Bolonha, Paris e Oxford nasceram espontaneamente (ex consuetudine) ao passo que outras surgiram por iniciativa papal ou principesca (ex privillegio) como é o caso da universidade de Nápoles fundada por Frederico II em I224, tendo em vista o objetivo de formar funcionários para a burocracia governamental. Também a Universidade de

I Neste e no próximo item retomo aspectos desenvolvidos em SAVIANI, Dermeval. "Universidade hoje: mutações de uma instituição milenar”. In: MACIEL, Adriana M. da Rocha et alii (org.). Universidade Hoje: o que precisa ser dito? Santa Maria: Editora UFSM, 20I2, p. 169-182.

2 Esses esclarecimentos foram prestados ao autor em entrevista concedida pelo Prof. Gian Paolo Brizzi, em 02/02/1995, no Departamento de História da Universidade de Bolonha.

3 DOLCINI, Carlo. "Pepo, Irnerio, Graziano. Alle origini dello 'Studium' di Bologna”. In: CAPITANI, Ovidio (a cura di). L'Università a Bologna. Personaggi, momenti e luoghi dalle origini al XVI secolo. Bologna: Edizioni Amilcare Pizzi, I987, p. I7.

4 CLAUSSE, Arnould. In: DEBESSE, Maurice e MIALARET, Gaston. Tratado das ciências pedagógicas, vol. 2 (História da Pedagogia). São Paulo: Nacional/Ed. USP, 1977, p. 164-167.

5 VERGER, Jacques. In: MIALARET, Gaston; VIAL, Jean. Histoire mondiale de L'Education. Paris: PUF, vol. 1, I98I, p. 289-29I.

$48 \cdot$ ano XI, n. I6, $2020 \cdot \mathrm{ISSN} 2179-5487$ 
Salamanca foi criada em I2I8 por Afonso IX, rei de León, como "Estudo Geral” e transformada em Universidade por Afonso X, o sábio, rei de Castela e León. Em I255 o título de Universidade foi confirmado por Bula Papal de Alexandre IV. Outra forma de surgimento de universidades era por migração (ex migratione) como ocorreu com a Universidade de Pádua, que se constituiu por migração de Bolonha, isto é, através de estudantes e professores que, em razão de conflito com a administração comunal, se transferiram para Pádua dando origem, ali, a uma nova universidade a partir de I222; o mesmo ocorreu com a Universidade de Cambridge que nasceu em 1208 por migração de Oxford, sendo oficialmente reconhecida apenas em I3I8. ${ }^{6}$ A primeira universidade em Portugal foi instituída por D. Dinis em I290, em Lisboa, sendo transferida para Coimbra em 1308 pelo mesmo D. Dinis. Regressou a Lisboa por ordem de D. Afonso IV em I338, voltou a Coimbra em 1354, mas retornou a Lisboa por iniciativa de D. Fernando em 1377. Finalmente, D. João III a fixou definitivamente em Coimbra em 1537.7

As universidades de Bolonha e de Paris se constituíram em referência para o reconhecimento das novas instituições que, via de regra, as tomavam como modelos:

Paris e Bolonha foram os protótipos das universidades medievais. Paris, chamada por Mullinger de "o Sinai da instrução" na Idade Média, serviu de modelo para as universidades de Oxford e Cambridge na Inglaterra; de Praga, Viena, Heidelberg e Colônia na Germânia, enquanto Bolonha inspirou principalmente as universidades da Itália, exceto a de Nápoles, as de Montpellier e Grenoble na França, e outras. ${ }^{8}$

Surgidas na Idade Média as universidades se constituíram como corporações destinadas à formação dos profissionais das "artes liberais”, isto é, intelectuais, por oposição àqueles das “artes manuais” que eram formados nas corporações de ofício.

Vemos que a questão da autonomia já começa a se pôr para as universidades desde suas origens. Com efeito, a migração de Bolonha que deu origem à Universidade de Pádua decorreu das pressões do poder comunal (municipal) para controlar a universidade. E, no caso da Universidade de Paris, professores e estudantes conviveram com as pressões, seja do poder secular, seja da Igreja. Assim, "para escapar à polícia e à justiça do rei”, ’ mestres e alunos se apoiavam na Igreja. Mas em breve eles sentiriam os efeitos dessa dependência em relação à Igreja sobre sua autonomia e sua liberdade intelectual. A principal resistência contra a autonomia de mestres e estudantes veio do Bispo de Paris e do Chanceler de Notre-Dame. Assim, por volta de II7o "apareceu a primeira forma - ainda embrionária - de associação

6 VERGER, Jacques. As universidades na Idade Média. São Paulo: Ed. UNESP, 1990, p. 4I-45.

7 NUNES, Ruy Costa. História da educação na Idade Média. São Paulo: EPU/Edusp, 1979, p. 220.

8 Ibidem, p. 219.

9 VERGER, Jacques. As universidades na Idade Média. São Paulo: Ed. UNESP, 199o, p. 33. 


\section{REVISTA ANGELUS NOVUS}

entre os mestres das escolas parisienses." ${ }^{\text {ю }}$ Eis porque se considera o ano de II7o como o marco de surgimento da Universidade de Paris. E foi justamente no Papa que "os mestres e estudantes parisienses dispuseram de um aliado todo-poderoso":

As razões que levaram os papas do século XIII, e em primeiro lugar Inocêncio III, a se mostrarem, diante desse movimento inovador que era o desenvolvimento das universidades, mais benévolos do que os bispos, podem ser concebidas: desejo de, graças às universidades, aumentar a centralização da Igreja, desejo de dotar a cristandade de grandes centros de estudos e de pesquisas religiosas diretamente ligadas ao papado, nesses anos em que o que fora adquirido na Reforma do século XI esgotara-se claramente. É certo, em todo o caso, que o auxílio trazido pelos papas aos mestres parisienses não era desinteressado e que, se lhes permitiam escapar à jurisdição do bispo e de seu chanceler, era para colocá-los sob o controle direto da Santa Sé."

A partir dessa origem medieval a universidade foi se desenvolvendo e se constituindo como o lugar principal da realização de pesquisas até que, no final do século XVIII e início do século XIX, ocorre um distanciamento entre, por um lado, os currículos tradicionais originários da Idade Média, centrados na teologia, direito e medicina, aliados aos que posteriormente foram introduzidos a partir do antigo sistema das artes liberais acrescidos de estímulos novos provenientes das Academias (filosofia e filologia clássica e moderna) e, por outro lado, os currículos mais novos, de caráter técnico-científico, próprios de um período em que o artesanato já havia sido suplantado pela manufatura e, em seguida, pela grande indústria implantada em consequência da revolução industrial. ${ }^{12} \mathrm{E}$ foi justamente nesse momento que a universidade se despiu de sua crosta medieval, dando origem à universidade moderna. Isso pode ser constatado com as universidades italianas que mantiveram seu caráter medieval até o início do século XIX, então rompido sob pressão do modelo napoleônico. Essa transformação pode ser ilustrada com o caso da Universidade de Pádua que na última década do século XVIII era ainda "uma universidade medieval numa época moderna", vindo a se modernizar apenas com o domínio de Napoleão no então Reino de Itália, entre I805 e I8I3. ${ }^{13}$ Pode-se, pois, dizer que a universidade, tal como a conhecemos atualmente, teve a sua configuração institucional definida na primeira metade do século XIX.

É também nesse momento que se configuram os três grandes modelos de universidade: $\mathrm{O}$ napoleônico, o anglo-saxônico e o prussiano. Este último se caracterizou com a fundação da Universidade de Berlim por Humboldt, em ı8ıo. Por isso esse modelo é também chamado de humboldtiano. A origem desses modelos se assenta nos elementos básicos constitutivos das

\footnotetext{
Io VERGER, Jacques. As universidades na Idade Média. São Paulo: Ed. UNESP, ı99o, p. 34.

II Ibidem, p. 35 .

I2 SANTONI RUGIU, Antonio. Nostalgia do mestre artesão. Campinas: Autores Associados, 1998, p. IO8-III.

I3 GHETTI, Maria Cecília. L'Università di Padova tra Repubblica Veneta e Restaurazione (I790-I8I7). Università di Padova, tesi di Laurea, 1982, p. I-IOI, 2I4-3I2.
}

$50 \cdot$ ano XI, n. I6, $2020 \cdot \mathrm{ISSN} 2 \mathrm{I79}-5487$ 
universidades contemporâneas: o Estado, a sociedade civil e a autonomia da comunidade interna à instituição. Esses elementos nunca aparecem de forma isolada. Conforme prevaleça um ou outro, tem-se um diferente modelo institucional. A prevalência do Estado dá origem ao modelo napoleônico; prevalecendo a sociedade civil tem-se o modelo anglo-saxônico; e sobre a autonomia da comunidade acadêmica se funda o modelo prussiano. ${ }^{14}$

Este último modelo, baseado na autonomia da comunidade interna, isto é, dos professores, propiciou o desenvolvimento mais intenso da pesquisa científica. Com a diáspora de cérebros provocada pelo nazismo, especialmente para os Estados Unidos, pode-se creditar ao modelo universitário dominante na Alemanha o impulso decisivo que se imprimiu ao desenvolvimento científico da maior potência mundial no século XX.

Entretanto, as universidades europeias vêm passando, desde a última década do século $\mathrm{XX}$, por um processo de significativa mutação da qual é expressão o chamado "Processo de Bolonha”.

\section{As universidades no Brasil: visão sintética}

Embora alguns dos colégios jesuítas no período colonial mantivessem cursos de filosofia e teologia, o que dá respaldo à tese de que já existia ensino superior nessa época no Brasil, os cursos superiores propriamente ditos começaram a ser instalados a partir de $1808 \mathrm{com}$ a chegada de D. João VI quando, em consequência do bloqueio napoleônico a Portugal, o Brasil se transformou na sede do império português. Surgiram, então, os cursos de engenharia da Academia Real da Marinha (I808) e da Academia Real Militar (I8Io), o Curso de Cirurgia da Bahia (I808), de Cirurgia e Anatomia do Rio de Janeiro (I808), de Medicina (I809), também no Rio de Janeiro, de Economia (I808), de Agricultura (I8I2), de Química (química industrial, geologia e mineralogia), em I8I7, e o Curso de Desenho Técnico (I818). Vê-se que se tratava de cursos superiores isolados, isto é, não articulados no âmbito de universidades, no espírito das "aulas régias" instituídas pelas Reformas Pombalinas da Instrução Pública.

Após a independência, por decreto de D. Pedro I de II de agosto de 1827 , foram criadas, nesse mesmo ano, as Faculdades de Direito de São Paulo e de Olinda sendo que esta última foi transferida para Recife em I854. Em 1934, com a fundação da Universidade de São Paulo, a Faculdade de Direito de São Paulo, sediada no Largo de São Francisco, a ela foi incorporada, o mesmo tendo ocorrido com a Faculdade de Direito do Recife, que se incorporou à Universidade Federal de Pernambuco, criada em 1946. 


\section{REVISTA ANGELUS NOVUS}

De modo geral, aos cursos criados por D. João VI - acrescidos do alargamento da Academia de Medicina para abranger cursos de Farmácia, Obstetrícia e Odontologia, mais alguns cursos na área de engenharia - e às duas mencionadas faculdades de direito, resume-se o ensino superior no Brasil até o final do Império. Duas características lhes são comuns: tratase de cursos (ou faculdades) isolados e são todos eles públicos; mantidos, portanto, pelo Estado. Mas já no final do império ganhou força o movimento pela desoficialização do ensino, que era uma bandeira dos positivistas, e pela defesa da liberdade do ensino, uma bandeira dos liberais.

Essa influência do positivismo, que marcou a proclamação da república brasileira a ponto de deixar inscrito na bandeira nacional o lema "ordem e progresso", foi uma característica do século XIX em decorrência da incorporação dos conhecimentos científicos ao desenvolvimento econômico capitalista. No Brasil, porém, a presença do positivismo, mais do que estimular a visão cientificista, teve como resultado a redução do protagonismo do Estado na educação, de modo geral, e, especificamente, no desenvolvimento do ensino superior.

Assim, nas primeiras décadas republicanas, arrefeceu-se a iniciativa oficial e começaram a surgir instituições particulares de ensino superior, tais como a Universidade do Paraná que, fundada em 1912, foi desativada em 1920 por indução do governo federal, e a Universidade de Manaus, criada em 1909, mas dissolvida em 1926 com o esgotamento do ciclo econômico da borracha.

A Universidade Federal do Rio Grande do Sul surgiu da Escola de Farmácia e Química, criada em I895, e da Escola de Engenharia, fundada em I896. A essas se seguiram, em 1900, as Faculdades de Medicina e de Direito. Em 1934, essas escolas, acrescidas das Faculdades de Agronomia e Veterinária, de Filosofia, Ciências e Letras e do Instituto de Belas Artes, constituíram a Universidade de Porto Alegre, transformada, em 1947, na Universidade do Rio Grande do Sul, que foi federalizada em 1950.

A de Minas Gerais surgiu em 1927 por iniciativa privada, contando com subsídio do governo estadual, e foi federalizada em 1949, dando origem à atual Universidade Federal de Minas Gerais.

A Universidade da Bahia foi constituída em 1946 incorporando as Escolas de Cirurgia, criada em 1808, Farmácia (1832), Odontologia (1864), a Academia de Belas Artes (1877), Direito (I89I) e a Politécnica (I896), acrescidas da Faculdade de Filosofia, Ciências e Letras, criada em 194I. Em 1950, ela foi federalizada transformando-se na atual Universidade Federal da Bahia.

A Universidade do Rio de Janeiro foi constituída em 1920 pela reunião da Faculdade de Medicina e Cirurgia surgida dos cursos criados por D. João VI em I8o8, e da Escola Politécnica, cuja origem remonta à fundação, em 1792, da Real Academia de Artilharia, 
Fortificação e Desenho e da Faculdade de Direito, criada em i882. A essas unidades universitárias foram acrescidas, posteriormente, a Faculdade Nacional de Belas Artes e a Faculdade Nacional de Filosofia. Em 1937, passou a se chamar Universidade do Brasil e, em 1965, recebeu o nome atual de Universidade Federal do Rio de Janeiro.

Foi após a Revolução de 1930 que se retomou o protagonismo do Estado nacional na educação com a criação, já em outubro desse ano, do Ministério da Educação e Saúde Pública e com os decretos da chamada Reforma Francisco Campos, em I93i, entre os quais se situam o que estabeleceu o Estatuto das Universidades Brasileiras e o que reformou a Universidade do Rio de Janeiro.

Efetivamente, foi a partir da aprovação do Estatuto que as universidades começaram a se caracterizar mais claramente no Brasil, tendo sido criada, em 1934, a Universidade de São Paulo e, em 1935, a Universidade do Distrito Federal, por iniciativa de Anísio Teixeira, que teve duração efêmera, tendo sido extinta pelo Decreto n. I063 de 20 de janeiro de 1939, ocasião em que seus cursos foram incorporados à Universidade do Brasil, que havia sido organizada pela Lei n. 452 de 5 de julho de 1937. Ainda na década de 1930 se organizava o movimento estudantil com a criação da União Nacional dos Estudantes (UNE), em 1938. Em I94I, surgiu a Pontifícia Universidade Católica do Rio de Janeiro (PUC-Rio) e, em 1946, a Pontifícia Universidade de São Paulo (PUC-SP). Na década de 1950, a rede federal se ampliou especialmente com a federalização de instituições estaduais e privadas, estendendo-se pelas décadas de 1960 e 1970 o processo de criação de novas universidades federais.

Em síntese, podemos considerar que no Brasil, desde a criação dos cursos superiores por D. João VI a partir de I8o8, não obstante a tendência à privatização que se esboçou no final do Império e ao longo da Primeira República, mas revertida com a instituição do regime universitário por ocasião da reforma Francisco Campos em 1931, passando pela reforma universitária instituída pela Lei n. 5.540 de 28 de novembro de 1968, prevaleceu o modelo napoleônico caracterizado pela forte presença do Estado na organização e regulação do ensino superior, em especial no caso das universidades.

No entanto, a partir da década de 1980, começou a se manifestar uma tendência a alterar esse modelo, operando-se um deslocamento no padrão de ensino superior no Brasil. Esse deslocamento tem origem na distinção entre universidades de pesquisa e universidades de ensino introduzida, em 1986, pelo GERES (Grupo Executivo para a Reformulação do Ensino Superior) criado pelo Ministério da Educação. Desde então o modelo napoleônico, que marcou fortemente a organização da universidade no Brasil, vem sendo reajustado pela incorporação de elementos do modelo anglo-saxônico em sua versão norte-americana. Nesse modelo a prevalência da sociedade civil enseja um maior estreitamento dos laços da universidade com as demandas do mercado. 


\section{REVISTA ANGELUS NOVUS}

É essa a situação que estamos vivendo hoje, quando vicejam os mais diferentes tipos de instituições universitárias oferecendo cursos os mais variados em estreita simbiose com os mecanismos de mercado. Aprofunda-se, assim, a tendência a tratar a educação superior como mercadoria entregue aos cuidados de empresas de ensino que recorrem a capitais internacionais com ações negociadas na Bolsa de Valores. Essa tendência atinge agora o paroxismo, com os ataques à educação pública desferidos pelo atual governo federal presidido por Bolsonaro.

\section{A questão da Autonomia Universitária no Brasil}

Como vimos no breve resumo apresentado no item anterior, a instituição universitária só veio a se configurar mais nitidamente no Brasil em meados do século XX. Assim, após o decreto que definiu o Estatuto das Universidades Brasileiras em I93I, à parte a existência efêmera da Universidade do Distrito Federal, tivemos a criação da Universidade de São Paulo, em 1934, e a organização da Universidade do Brasil, em 1937, ambas constituídas, ainda, pela reunião de escolas isoladas anteriormente existentes. E após a queda do Estado Novo esse processo se ampliou com a criação de universidades federais por meio da federalização de faculdades isoladas, particulares ou estaduais, ocorrendo posteriormente a fundação de novas universidades federais e, de modo especial a partir da década de 1980, o surgimento de universidades estaduais e particulares. Podemos considerar que a primeira universidade criada como tal, isto é, sem se constituir pela reunião de faculdades isoladas, foi a Universidade de Brasília, inaugurada em 2I de abril de 1962. Nesse momento nos encontrávamos em plena efervescência no que se refere à questão universitária, tendo como um de seus principais protagonistas a União Nacional dos Estudantes (UNE).

A UNE foi fundada no II Congresso Nacional de Estudantes realizado em dezembro de 1938, no qual foi Aprovação um Plano de Sugestões para uma Reforma Educacional Brasileira. Nesse plano já constavam, como o item IV, sugestões para a reforma universitária, não sendo "exagero afirmar que a União Nacional dos Estudantes nasceu dentro de um projeto de reforma do ensino superior elaborado pelos próprios estudantes." "is Mas será no final da década de 1950 e início dos anos 1960, no contexto do nacionalismo desenvolvimentista, que a UNE, incentivada pelo ISEB, em especial por Álvaro Vieira Pinto, se engajará fortemente no movimento pela reforma universitária, elencada como uma das Reformas de Base do governo Jango. E é nesse contexto que emergirá a questão da Autonomia Universitária revestida, porém, de um caráter polêmico.

Is CUNHA, Luiz Antônio Constant Rodrigues da. A universidade crítica: o ensino superior na República populista. $2^{\underline{a}}$ ed. Rio de Janeiro: Francisco Alves, 1989, p. 207.

$54 \cdot$ ano XI, n. I6, 2020 $\bullet$ ISSN 2179-5487 
No I Seminário Nacional de Reforma Universitária, realizado pela UNE em Salvador, de 20 a 27 de maio de 196I, a "autonomia da universidade” integrou o tópico II do temário de seis tópicos elaborado previamente em sessão preparatória que aprovou, além do temário, o regimento interno do seminário. Os resultados do Seminário foram objeto de um relatório final divulgado sob o nome de "Carta da Bahia". Nesse documento se defendia como necessária a reforma universitária na qual a autonomia da universidade figura como o primeiro passo:

O primeiro passo da reforma seria, então, a conquista da autonomia da universidade diante do governo, transformando-a em autarquia ou fundação, de modo que pudesse ter liberdade de elaborar os orçamentos, recebendo recursos sem destinação específica; eleger internamente as direções, só entrando o governo para a nomeação; capacidade de alterar os estatutos, dentro de princípios gerais fixados pelo governo; liberdade para criar ou suprimir matérias, mantendo as "definidoras do curso"; liberdade para modificar currículos e programas, podendo experimentar novos métodos de ensino, modificar sistemas de ingresso e aprovação. ${ }^{16}$

No entanto, essa posição em defesa da Autonomia Universitária acabou sendo revertida no II Seminário Nacional de Reforma Universitária realizado em Curitiba, de 17 a 24 de março de 1962, da qual resultou a "Carta do Paraná” que divulgou a análise da universidade realizada em cinco tópicos, a saber: I - Do ponto de vista estrutural; II - do ponto de vista regional; III - do ponto de vista cultural; IV - do ponto de vista político-social; V teorização da universidade.

Vê-se que o tema da Autonomia Universitária está ausente da programação desse II Seminário não figurando, pois, na "Carta do Paraná". De fato, já no primeiro seminário, a defesa da autonomia como primeiro passo da reforma universitária não estava isenta de restriçóes, pois logo após enunciar em que consistia o princípio da autonomia se afirmava que esse princípio somente permitiria encaminhar a reforma "na direção desejada, se houvesse uma mudança interna de poder, modificando a 'verdadeira luta de classe' entre professores e estudantes. ${ }^{17}$ E, por ocasião do II Seminário realizado em Curitiba, os estudantes já contavam com a contribuição de Álvaro Vieira Pinto que, com base em uma conferência proferida em Belo Horizonte sobre “a questão da universidade”, transformada em livro pouco antes da realização do II Seminário e Publicação em seguida pela própria editora da UNE, havia descartado a Autonomia Universitária. No referido livro, Vieira Pinto argumenta que "no país onde a universidade é peça do dispositivo de domínio das camadas sociais espoliadoras”, a Autonomia Universitária resulta contrária aos interesses do povo, "pois ajuda, mediante as ficções jurídicas que engendra, a manter distante do controle social, pelas massas 16 Ibidem, p. 225-226.

I7 CUNHA, Luiz Antônio Constant Rodrigues da. A universidade crítica: o ensino superior na República populista. $2^{a}$ ed. Rio de Janeiro: Francisco Alves, I989, p. 226. 


\section{REVISTA ANGELUS NOVUS}

trabalhadoras, esse instituto, que se julga entidade à parte", ${ }^{18}$ destacando, mais adiante: "só na sociedade que já resolveu os seus conflitos básicos, e estabeleceu, entre outras medidas, o cogoverno de docentes e estudantes, a universidade pode e deve ser autônoma", ${ }^{19}$ para arrematar taxativamente:

No caso brasileiro, o que há a fazer é justamente reduzir cada vez mais a autonomia didática e administrativa da universidade, a fim de torná-la mais dependente das forças sociais progressistas, as massas e o povo em geral, representados pelos agentes políticos da comunidade e sobretudo pelos estudantes. Nas atuais condições, a autonomia é um mito que só convém à classe professoral dominante para lhe assegurar o ócio e a irresponsabilidade perante o restante da nação, sustentando-lhe o ridículo e prejudicial orgulho de "falange eleita" da cultura. ${ }^{20}$

Paralelamente à discussão sobre a reforma universitária desencadeada pelo movimento estudantil, tramitava no Congresso Nacional o projeto de LDB cuja aprovação resultou na promulgação, em 20 de dezembro de 196I, de nossa primeira Lei de Diretrizes e Bases da Educação Nacional (Lei no 4.024/6I) que contemplou a questão da autonomia no Art. 8o, assim redigido: "As Universidades gozarão de autonomia didática, administrativa, financeira e disciplinar, que será exercida na forma de seus estatutos”. E especificou, nos parágrafos Io, ㄴo e $3^{\circ}$, em que consistem respectivamente a autonomia didática, administrativa e financeira.

Mas essa mobilização foi interrompida pelo golpe empresarial-militar de 1964. O Movimento Estudantil acabou se constituindo na principal força de resistência à ditadura militar; e, na esteira do movimento mundial que ficou conhecido como "maio de 1968 ", cujo epicentro foi Paris, os estudantes tomaram as universidades em junho de 1968, organizaram cursos pilotos, ensaiando fazer a reforma universitária com as próprias mãos, mantendo-se no controle da instituição durante o mês de julho e ao longo de todo o segundo semestre. Tal movimento levou o governo a raciocinar na forma de "façamos a reforma antes que os estudantes a façam”, criando um Grupo de Trabalho por Decreto presidencial baixado em 2 de julho de 1968, portanto no auge da crise estudantil e atribuindo ao referido GT a realização, no prazo de 30 dias, de estudos com o objetivo de garantir a "eficiência, modernização e flexibilidade administrativa” da universidade brasileira.

Ao iniciar seus trabalhos, o Grupo da Reforma Universitária já dispunha de um conjunto de subsídios que vinha desde o Relatório Atcon, passando pelo relatório da Equipe de Assessoramento ao Planejamento do Ensino Superior e pelo Relatório Meira Matos, até os estudos patrocinados pelo IPES. ${ }^{21}$ Mas se viu diante da tarefa de tentar conciliar duas

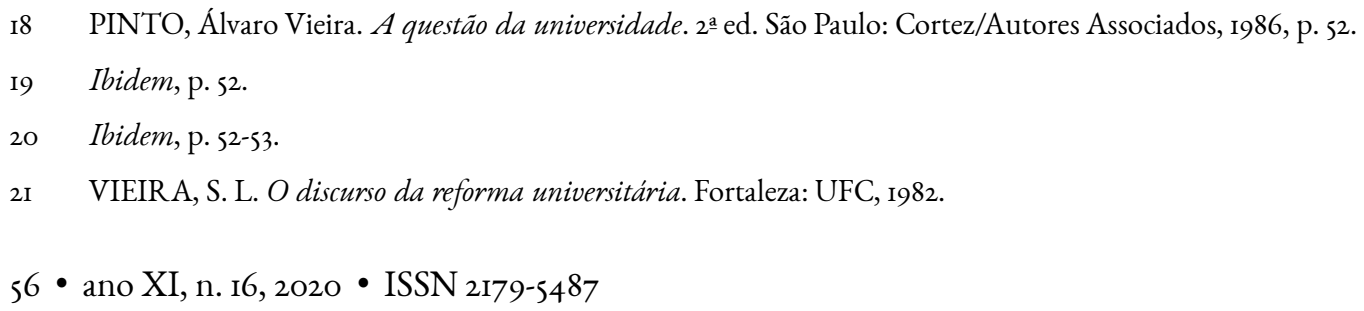


SAVIANI • "Autonomia Universitária e suas vicissitudes na universidade brasileira”

demandas contraditórias: as exigências dos grupos ligados ao governo, que assumiu o poder mediante um golpe de força, e que buscavam vincular mais fortemente o ensino superior aos mecanismos de mercado e ao projeto político de modernização em consonância com os requerimentos do capitalismo internacional; e as reivindicações dos estudantes e dos jovens postulantes a estudantes universitários assim como dos professores que defendiam a abolição da cátedra, a Autonomia Universitária, mais verbas para desenvolver pesquisas e mais vagas para ampliar o raio de ação da universidade. É nesse contexto que o Relatório do Grupo de Trabalho da Reforma Universitária, tendo em vista a segunda demanda, contemplou a questão da Autonomia Universitária que, mantida no projeto que deu entrada no Congresso

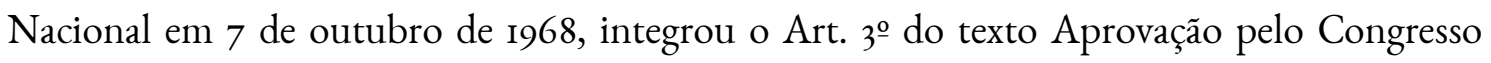
com a seguinte redação:

Art. $3^{\text {o }}$ - As universidades gozarão de autonomia didático-científica, disciplinar, administrativa e financeira, que será exercida na forma da lei e dos seus estatutos.

$\S$ ํo- - A autonomia didático-científica e disciplinar consiste na faculdade de:

a) criar, organizar e modificar e extinguir cursos, atendendo à legislação vigente e às exigências do meio social, econômico e cultural;

b) fixar os currículos de seus cursos, observadas as bases mínimas estabelecidas pelo Conselho Federal de Educação;

c) estabelecer planos e projetos de investigação científica em qualquer área de sua competência;

d) estabelecer o calendário escolar e regimes de trabalho didático e científico de suas diferentes unidades, sem outras limitações a não ser as previstas em lei;

e) fixar os critérios para admissão, seleção, promoção e habilitação de alunos;

f) conferir graus, diplomas, títulos e outras dignidades universitárias;

g) elaborar o próprio código disciplinar para o corpo docente, o discente e o técnicoadministrativo.

$\$ 2^{\circ}-$ A autonomia administrativa consiste na faculdade de:

a) elaborar a reforma, submetendo à aprovação do Conselho de Educação competente, os próprios estatutos e os regimentos de suas unidades;

b) indicar o Reitor, o Vice-Reitor e outros elementos da direção, segundo as normas previstas nesta Lei;

c) contratar professores e auxiliares de ensino ou promover sua nomeação atendendo aos preceitos legais vigentes;

d) firmar contratos, acordos e convênios;

e) aprovar e executar planos, programas e projetos de investimentos referentes a obras, serviços e aquisições em geral;

f) admitir e demitir quaisquer funcionários, dispor sobre regime de trabalho e remuneração dentro de suas dotaçôes orçamentárias e outros recursos financeiros;

$\$ 3^{\circ}-$ A autonomia financeira consiste na faculdade de: 


\section{REVISTA ANGELUS NOVUS}

a) administrar os rendimentos próprios e o seu patrimônio e dele dispor, na forma prevista no ato de constituição, nas leis e nos estatutos respectivos;

b) receber subvenções, doações, heranças, legados e cooperação financeira resultante de convênios com entidades públicas ou privadas;

c) realizar operações de crédito ou de financiamento, com aprovação do Poder competente, para aquisição de bens imóveis, instalações e equipamentos;

d) organizar e executar o orçamento total de sua receita e despesa, devendo os responsáveis pela aplicação dos recursos prestar contas anuais;

$\S 4^{\circ}$ - Os estatutos das universidades poderão prever outras atribuições, além das constantes do presente artigo.

O governo, por sua vez, lançou mão de seu direito de veto para excluir todas as medidas que não estivessem em sintonia com sua visão de universidade. E nessa condição estava incluída a questão da autonomia. Assim, foi mantido apenas o caput do artigo $3^{\circ}$. Os $\oint 1^{\circ}, 2^{\circ}, 3^{\circ}$ e $4^{\circ}$, com todas as respectivas alíneas, foram sumariamente vetados. E a visão do governo foi assegurada pelo Decreto 464 de II de fevereiro de 1969, que regulamentou a implantação da Reforma Universitária instituída pela Lei 5.540 de 28 de novembro de 1968. E o tema da Autonomia Universitária está inteiramente ausente do referido decreto de regulamentação que, inclusive, por meio do Art. 19, revogou o Art. 8o da Lei no 4.024, de 20 de dezembro de 196I que assegurava às universidades a prerrogativa da autonomia.

Finalmente, o princípio da Autonomia Universitária foi contemplado no Art. 207 da Constituição da República Federativa do Brasil, promulgada em os de outubro de 1988, com o seguinte enunciado que permanece em vigor:

Art. 207. As universidades gozam de autonomia didático-científica, administrativa e de gestão financeira e patrimonial, e obedecerão ao princípio de indissociabilidade entre ensino, pesquisa e extensão.

Apesar da clareza do enunciado é forçoso observar que fica, ainda, num plano genérico. Talvez, do ponto de vista jurídico, fosse necessário proceder a uma regulamentação desse dispositivo explicitando em que consiste cada um dos aspectos contemplados no conceito de autonomia e indicando as medidas necessárias para se assegurar seu exercício efetivo.

\section{Conclusão}

Vimos, no primeiro tópico deste artigo, que a emergência da universidade moderna no início do século XIX trouxe consigo a configuração dos três grandes modelos de universidade: o napoleônico, o anglo-saxônico e o prussiano ou humboldtiano, sendo também indicado que é este último modelo que se caracteriza exatamente pela prevalência da autonomia da 
comunidade acadêmica interna à universidade. E, no segundo tópico, vimos que o modelo prevalecente no Brasil é o napoleônico que, nos últimos 30 anos, vem sofrendo certo refluxo com abertura para o modelo anglo-saxônico na versão norte-americana. Mas vimos igualmente que os três elementos (Estado, sociedade civil e comunidade interna à universidade) nunca existem isolados, estando presentes, portanto, nos três modelos de universidade. Assim, o que distingue um modelo do outro não é a exclusividade, mas a prevalência de determinado aspecto. Portanto, a autonomia não deve ser entendida simplesmente como a característica de determinado modelo de universidade, mas como uma propriedade inerente à natureza própria da universidade. E isto - assim entendemos - fica evidenciado pelo complemento do Art. 207 da Constituição Brasileira que, ao enunciar a prerrogativa da autonomia das universidades, adiciona que as mesmas "obedecerão ao princípio de indissociabilidade entre ensino, pesquisa e extensão”. Ora, como evidenciou o êxito da universidade humboldtiana, o atributo da autonomia é indispensável ao exercício da atividade científica. E, como a universidade não é simplesmente um instituto científico, mas uma instituição de ensino que tem a incumbência de formar cientistas e os demais profissionais, sempre tendo como referência a fundamentação científica, ela deve fazê-lo pela produção da ciência (pesquisa) e pela sua divulgação (extensão) a mais ampla possível, contribuindo, assim, para a difusão em toda a sociedade de uma concepção científica do mundo e da vida.

Em suma, independentemente do modelo de universidade que se venha a adotar, não se pode abrir mão da autonomia, sob pena de se descaracterizar o próprio sentido da instituição universitária. Cabe, portanto, considerar as implicações, para a Autonomia Universitária, da adoção deste ou daquele modelo de universidade. Antes, porém, cumpre deixar clara a distinção entre modelo de universidade e entidade mantenedora de universidade. Com efeito, universidade pública é aquela que é mantida com recursos públicos; e universidade privada é a que é mantida com recursos privados. E em ambos os casos é possível a adoção de qualquer um dos três modelos mencionados. No Brasil, podemos dizer que o modelo dominante é o napoleônico dado o peso do Estado. E isso vale para todas as modalidades de instituiçóes, sejam elas públicas (federais, estaduais ou municipais) ou privadas (com e sem fins lucrativos, comunitárias, confessionais e filantrópicas); tanto sob o aspecto administrativo-financeiro como didático-científico; seja pelo financiamento, direto no caso das públicas e indireto, no caso das privadas por meio de bolsas, apoio a projetos de pesquisa, convênios e transferências do tipo Fies e Prouni; seja pelas normas que devem ser seguidas por todas as instituições quanto ao uso dos recursos e prestação de contas e quanto aos currículos, avaliação e controle dos resultados. 


\section{REVISTA ANGELUS NOVUS}

Quando consideramos a situação vigente no Brasil parece que as instituições que atingiram um grau maior de autonomia foram as universidades estaduais paulistas a partir do Decreto no 29.598, de o2 de fevereiro de 1989, cuja ementa assim foi enunciada: Dispóe sobre providências visando a autonomia universitária. Por esse decreto o governo passou a repassar um percentual da arrecadação do Imposto sobre Circulação de Mercadorias e Serviços (ICMS), ficando as decisões sobre a destinação, distribuição e gestão dos recursos a cargo das universidades individualmente, ou conjuntamente por meio do Conselho de Reitores das Universidades Estaduais Paulistas.

Outro ponto a considerar é que o exercício da autonomia deve corresponder à comunidade acadêmica interna às instituições. Assim, por vezes se atribui maior grau de autonomia às universidades privadas, uma vez que elas não se encontram subordinadas diretamente às autoridades estatais, não estando também sujeitas às restrições dos órgãos de controle do serviço público. No entanto, esse suposto maior grau de autonomia tende a se limitar aos dirigentes e às entidades mantenedoras, não se estendendo, via de regra, à comunidade acadêmica interna, isto é, aos professores e estudantes, mesmo porque a legislação limita a exigência de gestão democrática às instituições públicas, não alcançando as instituições privadas. Assim, a rigor, não se poderia considerar que se trata, aí, da Autonomia Universitária propriamente dita.

Enfim, embora não seja motivo para deixarmos de lutar pela efetivação do princípio da Autonomia Universitária, não deixa de ser procedente a advertência de Álvaro Vieira Pinto de que só na sociedade que já resolveu seus conflitos básicos a universidade pode e deve ser autônoma. De fato, somente quando a universidade tiver voltado suas atividades de pesquisa, ensino e extensão aos interesses e necessidades do conjunto da população ela poderá exercer em plenitude sua autonomia. Por isso, a luta em defesa da universidade e em favor do pleno exercício da autonomia deverá estar articulada à mobilização de toda a população, engajando as lideranças de todas as categorias de trabalhadores e dos movimentos sociais populares na defesa da soberania do país e na transformação da sociedade brasileira.

$60 \cdot$ ano XI, n. 16, 2020 • ISSN 2179-5487 